Despite a rapidly growing enthusiasm for the use of information and communications technologies (ICTs) in developing country agriculture, many questions remain on the effectiveness of ICT-based approaches. In the case of Ethiopia, an IFPRI-led and PIM-supported study highlighted the benefits of a large-scale video-mediated approach for agricultural advisory services. The Government of Ethiopia used these results to make a significant investment in digitizing agricultural advisory services.

In 2019, the Government of Ethiopia, in partnership with the Bill \& Melinda Gates Foundation and the United Kingdom's Department for International Development (now Foreign, Commonwealth \& Development Office), launched a country-wide project called "Digitalizing Agricultural Advisory Services", also known as FarmStack.

FarmStack uses a digital platform that aims to boost agricultural productivity by delivering location- and time-specific advice to farmers across multiple channels including video, SMS, and radio. As a key component of this platform, extension staff produce short videos that feature locally relevant content and local actors speaking in local languages. These videos are then screened for farmers by extension agents using low cost projectors, with Q\&A sessions during and after the screenings.

This project emerged as a result of the success of Digital Green's video-mediated extension in the country. An impact evaluation conducted in 2017-2018 by IFPRI with support from Digital Green, the Ministry and regional bureaus of Agriculture, the Bill \& Melinda Gates Foundation, USAID's Feed the Future Developing Local Extension Capacity (DLEC) project and PIM provided evidence on the benefits of this approach. Researchers explored the impact of video-mediated extension across three main crops (maize, teff and wheat) and three agricultural practices (row planting, lower seeding rates and urea side dressing), and found that this form of extension reached a larger audience than traditional extension-delivery approaches and enhanced farmers' knowledge and adoption of improved practices. In addition, videomediated extension led to greater participation and greater knowledge among women farmers.

IFPRI's presentation of the intermediate results of the evaluation to the Government of Ethiopia strongly influenced the government's decision to invest in FarmStack. FarmStack will receive US $\$ 17.5$ million from the Bill \& Melinda Gates Foundation and the United Kingdom's Foreign, Commonwealth \& Development Office over the period 2019-2024, with commensurate funding from the Government of Ethiopia. 


\section{Also see:}

Abate, G. T., Bernard, T., Makhija, S., Spielman, D. J. 2019. Accelerating technical change through video-mediated agricultural extension: Evidence from Ethiopia. IFPRI Discussion Paper 1851.

Washington, DC: International Food Policy Research Institute (IFPRI).

IFPRI and Digital Green. 2019. Accelerating technical change through video mediated agricultural extension. Poster. Montpellier: CGIAR System Organisation.

When saying 'see, it works!' isn't enough: Sharing results from an evaluation of video-mediated extension in Ethiopia (IFPRI Blog, August 8, 2018)

\section{About PIM}

Policies, Institutions, and Markets (PIM) is one of CGIAR's Global Integrating Programs, focused on addressing the policy, institutional, and market constraints to sustainable and equitable economic development and rural transformation. Such roadblocks include regulations restricting adoption of technologies by smallholder farmers, inefficient allocation of public resources, market failures or missing markets, weak property rights, restrictive gender norms and practices, and exposure of smallholders to shocks and risks. PIM aims to address these constraints through four main channels: global agenda setting, national policy support, program and market innovations, and capacity development.

www.pim.cgiar.org

This publication has been prepared as an output of the CGIAR Research Program on Policies, Institutions, and Markets (PIM) led by IFPRI and has not been independently peer reviewed. Any opinions expressed here belong to the author(s) and are not necessarily representative of or endorsed by IFPRI, PIM, or CGIAR.

\section{CGIAR RESEARCH PROGRAM ON POLICIES, INSTITUTIONS, AND MARKETS}

1201 Eye Street, NW, Washington, DC 20005 USA | T. +1-202-862-5600 | F. +1-202-862-5606 | Email: CRP-PIM@cgiar.org | www.pim.cgiar.org

Follow us on Twitter: @PIM_CGIAR and Facebook: /PIM.CGIAR 